\title{
Inclusão escolar e o planejamento educacional individualizado: estudo comparativo sobre práticas de planejamento em diferentes países
}

\author{
Gabriela Tannús-Valadão' (D) \\ Enicéia Gonçalves Mendes' (D)
}

\section{RESUMO}

Traça-se um panorama histórico acerca do conceito de plano educacional individualizado - PEI, apontando as consequentes mudanças nas práticas nele estabelecidas em decorrência da segregação e da inclusão escolar. Apresenta-se análise da legislação sobre PEI e dos modelos de execução desse tipo de planejamento em países, a saber: França, Itália, Estados Unidos e Brasil. O modelo de PEI da França é o que tem maior abrangência, visto que engloba todo o ciclo de vida. Nos Estados Unidos e na Itália, ele é exclusivo da vida escolar, embora seja enfatizada a importância de medidas de controle do processo de transição da escola para o trabalho e/ou comunidade. O Brasil não possui dispositivos na legislação que garantam que tais estudantes tenham um PEI baseado em suas peculiaridades, resultando num planejamento centrado mais nos serviços existentes do que nas necessidades dos alunos. Assim, ainda que a era anunciada seja de inclusão escolar, as práticas de planejamento não mudaram.

\section{PALAVRAS-CHAVE}

educação especial; educação inclusiva; inclusão escolar; plano educacional individualizado.

'Universidade Federal de São Carlos, São Carlos, SP, Brasil. 


\title{
SCHOOL INCLUSION AND INDIVIDUALIZED EDUCATIONAL PLANNING: A COMPARATIVE STUDY ON PLANNING PRACTICES IN DIFFERENT COUNTRIES
}

\begin{abstract}
An historical overview is outlined about the individualized educational plan (IEP) concept and the consequent changes in their practice due to school segregation and inclusion. Then, analyzing the legislation on IEP and the models of execution of this type of planning in other countries, namely: France, Italy, the United States and Brazil. The model of IEP in France is broader, encompassing the whole life cycle. In the United States and Italy, the model focuses on the exclusive planning of school life, although all emphasize the importance of measures to control the transition process from school to work or/and community. Brazil does not have provisions in legislation to ensure that such students have an IEP based on their peculiarities, resulting in a planning more strongly focused on the existing services rather than on student needs. Thus, although the announced era is of school inclusion, planning practices have not changed.

\section{KEYWORDS}

special education; inclusive education; school inclusion; individualized educational plan.

\section{INCLUSIÓN ESCOLAR Y EL PLANIFICACIÓN EDUCACIONAL INDIVIDUALIZADO: ESTUDIO COMPARATIVO SOBRE PRÁCTICAS DE PLANIFICACIÓN EN DIFERENTES PAÍSES}

\section{RESUMEN}

Se traza un panorama histórico sobre el concepto de programa educativo individualizado - PEI, apuntando los consecuentes cambios en las prácticas establecidas como consecuencia de la segregación y la inclusión escolar. Se presenta análisis de la legislación sobre PEI y los modelos de ejecución en países, a saber: Francia, Italia, Estados Unidos y Brasil. El modelo de PEI de Francia es el que tiene mayor alcance, ya que engloba todo el ciclo vital. En los Estados Unidos e Italia, esta planificación es exclusiva de la vida escolar, aunque se subraya la importancia de medidas de control del proceso de transición de la escuela al trabajo y/o comunidad. Brasil es el único que no tiene legislación que garanticen que tales estudiantes tengan un PEI basado en sus peculiaridades y eso ha resultado en una planificación tradicional de segregación escolar, centrada más en los servicios existentes que en las necesidades de los estudiantes. Así, aunque la era anunciada sea de inclusión escolar, las prácticas de planificación no cambiaron.

\section{PALABRAS CLAVE}

educación especial; educación inclusiva; inclusión escolar; programa educativo individualizado. 


\section{INTRODUÇÃO}

As políticas de inclusão em relação à escolarização do público-alvo da Educação Especial (PAEE) ${ }^{1}$ não são um tema novo. O que muda na discussão atual é o fato de não se pensar acerca desse assunto como algo a ser encoberto, excluído, marginalizado, pelo menos no âmbito das intenções. Ao contrário, as reflexões têm se conciliado com a possibilidade objetiva e real da escolarização do PAEE em ambiente regular junto aos seus pares, principalmente porque a inclusão escolar é considerada um imperativo moral para sociedade.

O objetivo do presente artigo consiste em, inicialmente, traçar um panorama histórico sobre o conceito plano educacional individualizado (PEI), apontando as implicações e consequentes mudanças da filosofia de escolarização em ambientes mais segregados até a adoção da inclusão escolar, que pressupõe que a melhor colocação seja a classe comum das escolas regulares. Em seguida, analisa-se a legislação sobre PEI e os modelos de execução desse tipo de planejamento em outros países, a saber: França, Itália, Estados Unidos e Brasil. A análise do planejamento educacional para o PAEE, no Brasil, é então contrastada com as práticas e propostas encontradas em outros países. Finalizando o estudo, argumenta-se sobre como melhorar a escolarização de alunos do PAEE, introduzindo o PEI como ferramenta na política educacional brasileira.

\section{BREVE HISTÓRICO SOBRE PLANO EDUCACIONAL INDIVIDUALIZADO}

A ideia de se planejar personalizadamente a educação de estudantes nasce com a própria educação ocidental. Em passagens do século V a.C. de Platão, citadas por Manacorda (1989), é possível constatar que, desde os primórdios, a educação começa de maneira elitizada, segregada e individualizada, pois apenas os homens filhos da classe dominante poderiam estudar e o percurso educativo começava, em primeiro lugar, com os pais, surgindo, em seguida, a nutriz (ama) e o tutor, com a finalidade de ensinar os valores e as condutas na tentativa de tornar a pessoa o melhor possível.

De modo semelhante, a Educação Especial, iniciada muitos séculos depois, lança mão da individualização de ensino para educar crianças e jovens PAEE. As primeiras iniciativas de Itard, por exemplo, para educar Vitor, o selvagem, datam do final do século XVI e começo do século XVII. Jean Itard defendia uma pedagogia para todos, baseada na observação e experimentação, método que permitia a percepção do desenvolvimento de cada aluno e de suas diferenças.

Assim, com o advento da ciência e a maior sistematização da educação e do ensino, em séculos seguintes, a literatura científica reforçou essa ideia e vem sendo cada vez mais taxativa quanto à necessidade do planejamento educacional talhado na individualidade de cada um, tanto para organizar e otimizar o percurso de desenvolvimento de estudantes, principalmente aqueles do PAEE, quanto para

1 Segundo a legislação brasileira, o atual PAEE é composto por pessoas com deficiência, transtorno global do desenvolvimento e altas habilidades/superdotação (Brasil, 2011). 
guiar a práxis em sala de aula e nas escolas. Esse planejamento assume especificações individualizadas, o que faz dele um mecanismo essencial para se garantir os resultados esperados no processo de escolarização diversificado desse alunado.

Entretanto, a Educação Especial mudou ao longo dos anos e, embora isso tivesse acontecido de modo não linear, pode-se identificar basicamente três fases em sua história, a começar pela fase da exclusão do seu público de qualquer tipo de escolarização, passando pela fase da segregação escolar, em que esse público começou a frequentar instituições com objetivos educacionais pedagógicos, ou não, mas num sistema paralelo em relação à educação geral, e, por fim, chegando à última fase de inclusão escolar, que é a escolarização do seu público-alvo no mesmo sistema de ensino dos demais alunos (Mendes, 2010). Ao longo dessas duas últimas fases, em que já se parte do princípio do direito à educação dessa população, é que começa a emergir o problema de planejar o ensino para esses estudantes que antes não frequentavam as escolas.

$\mathrm{Na}$ fase da segregação, o planejamento era centrado na instituição e tinha como objetivo específico alterar ou amenizar o déficit causado pela deficiência do estudante. Nesse sentido, os programas e serviços envolviam segregação, os alunos eram agrupados por deficiência, e seus planos eram similares ou padronizados para todas as pessoas de uma mesma instituição (Amando e McBride, 2001).

É possível identificar que esse mesmo tipo de PEI era o adotado pelo movimento da Escola Nova, que surge no final do século XIX. Segundo Alves (2010), esse movimento rompia com ideias, princípios, organização e finalidades educacionais da sociedade industrial, capitalista, e objetivava formar estudantes com conteúdo, desconsiderando a formação individual e integral das pessoas.

Com base no movimento de escola-novista, foram realizadas reformas pedagógicas, permitindo-se, ainda, a inserção das pesquisas e práticas da psicologia na educação, como, por exemplo, o uso dos testes de inteligência para identificar deficientes intelectuais. Pesquisadores e educadores como Maria Montessori, Seguin, Binet e Simon deram a base para a educação e, consequentemente, para o currículo das instituições que recebiam o alunado PAEE da época (Mendes, 2010).

Depois das duas primeiras Guerras Mundiais, e com o surgimento dos primeiros documentos sobre direitos humanos no mundo ocidental, a fase da inclusão escolar começa a ganhar força. De modo semelhante aos países europeus e ao norte-americano, pelo menos, no âmbito das intenções, as leis sobre integração escolar começam a se fortalecer nos anos de 1960 e 1970, o que também ocorreu no Brasil, particularmente, com as edições de 1961 e 1971 da Lei de Diretrizes e Bases da Educação (LDB).

A partir da década de 1970, constata-se uma mudança no foco do PEI para o PAEE. Antes, esse era baseado nos modelos médico e psicopedagógico de deficiência, estando o foco do diagnóstico centrado nos impedimentos, tendo em vista os interesses da instituição de atendimento. Com a filosofia de normalização, integração e, posteriormente, de inclusão escolar e social, o foco do planejamento passou a ser o próprio indivíduo (O'Brien e O'Brien, 2000).

O PEI centrado na pessoa assumiu como objetivo as experiências e situações de vida e passou a enfocar o desenvolvimento do indivíduo e o aprofundamento de suas relações pessoais e de sua vida em comunidade. Esse instrumento visa a 
transformar o papel da pessoa PAEE na sociedade com a mudança nos padrões existentes, tais como: nos aspectos financeiros, nas opções de serviços regulares, entre outros (Amando e McBride, 2001).

Os primeiros modelos de planejamento centrado na pessoa tinham em comum a ideia de que os meios pelos quais a pessoa está inserida devem demandar os serviços de acordo com sua necessidade e, por isso, deve ser compreendida por aqueles que prestarem serviços. Além de apresentar consistência interna com a forma pela qual as pessoas são, de fato, servidas.

Essas abordagens partilham ideias como: a normalização do ensino no ambiente natural da comunidade; a importância de se evitar rótulos que despersonalizam as pessoas e os procedimentos que discriminam com base na diferença; o fato de contemplar as vozes das pessoas PAEE e daqueles que as conhecem; e a ênfase na construção de relacionamentos, na individualização dos suportes, no aumento das expectativas de desenvolvimento das pessoas PAEE e na demanda para que as agências adotem novas formas de prover os serviços (O'Brien e O’Brien, 2000).

Keyes e Owens-Johnson (2003) fazem distinção entre esses dois modelos de planejamento (centrado na instituição versus centrado na pessoa), conforme sistematizado no Quadro 1.

Assim, com o movimento pela educação inclusiva, surgem, em diferentes países, legislações federais com dispositivos referentes ao PEI, que preconizam a escolarização de pessoas PAEE em escolas comuns e que diminuem a demanda de planejamento centrado na instituição, ampliando a demanda pelo planejamento centrado no indivíduo.

O modelo do planejamento centrado na pessoa pode ter variantes desde o planejamento focalizado, especificamente, no período de vida escolar, até o planejamento com vistas ao processo de desenvolvimento profissional, ou mesmo o planejamento que abrange além desse desenvolvimento, o ciclo vital da pessoa. De modo sintético, pode-se dizer que o planejamento individualizado pode ser tanto "escolar", quando se preocupa em atender às demandas escolares, ou "educacionais", com maior abrangência, por se preocupar em atender às demandas da vida em comunidade de modo geral e levando em consideração o ciclo vital do indivíduo, que envolve estabelecer metas em curto, médio e longo prazo.

De qualquer modo, a proposta do PEI pode ser traduzida como a forma de se produzir documentação ou registro com a finalidade de promover e garantir, como um contrato, a aprendizagem de estudantes PAEE por meio da ação compartilhada pelas pessoas responsáveis ou que deverão trabalhar com esses estudantes.

\section{CONCEITO DO PLANEJAMENTO EDUCACIONAL INDIVIDUALIZADO CENTRADO NO INDIVÍDUO}

O planejamento educacional pode ser compreendido como as ações prioritárias que devem ser realizadas em uma microrregião, de acordo com os recursos locais (Mittler, 2003), e visa a contemplar as necessidades da população à qual ele é direcionado (Giné e Ruiz, 1995). 
Já o currículo formal é o conteúdo padrão e oficial programado para todos os estudantes de uma classe, independentemente de sua limitação ou especificidade (Moreira e Baumel,2001). Stainback (2006) lembra que, pelo fato de não encontrarmos homogeneidade na sala de aula, a existência somente do currículo formal, sem diferenciações personalizadas, pode ser contestada desde o princípio. Para Schmidt e Garcia (2007), o significado do termo currículo é dado pelo contexto em que se insere, incluindo a sala de aula.

Assim, o PEI quebra a barreira do padrão, auxiliando o currículo oficial, especificando e estruturando o tipo de atividade e apontando qual apoio profissional é conveniente para um estudante PAEE, de modo que, com isso, não haja limite, ao contrário, haja estímulo no processo de ensino-aprendizagem.

Quadro 1 - Atributos do planejamento centrado na instituição e centrado na pessoa.

\begin{tabular}{|c|c|}
\hline $\begin{array}{c}\text { Planejamento } \\
\text { centrado na instituição }\end{array}$ & $\begin{array}{c}\text { Planejamento } \\
\text { centrado na pessoa }\end{array}$ \\
\hline 1. Conduzido por um ou poucos profissionais. & 1. Promovido por grupo de pessoas. \\
\hline $\begin{array}{l}\text { 2. Participantes são normalmente } \\
\text { adultos e profissionais. }\end{array}$ & $\begin{array}{l}\text { 2. Participantes envolvem profissionais, familiares, a } \\
\text { própria pessoa público-alvo da Educação Especial, } \\
\text { seus pares, ou seja, todos e todas que participam de } \\
\text { modo direto ou indireto do processo de escolarização. }\end{array}$ \\
\hline $\begin{array}{l}\text { 3. Processo orientado a uma } \\
\text { finalidade, designado a atender } \\
\text { requerimentos burocráticos. }\end{array}$ & $\begin{array}{l}\text { 3. Processo reflexivo e criativo, designado } \\
\text { para adquirir informações. }\end{array}$ \\
\hline $\begin{array}{l}\text { 4. Informações são prestadas, relatórios lidos, } \\
\text { dados de avaliações formais são valorizados. }\end{array}$ & $\begin{array}{l}\text { 4. Informações são compartilhadas e avaliações } \\
\text { formais e informais são valorizadas. }\end{array}$ \\
\hline $\begin{array}{l}\text { 6. Interesses pessoais ou de grupos } \\
\text { de profissionais são priorizados. }\end{array}$ & $\begin{array}{l}\text { 6. As várias ideias de todos os participantes na reunião } \\
\text { são altamente valorizadas, ou seja, todos têm voz. }\end{array}$ \\
\hline $\begin{array}{l}\text { 7. Perspectiva é baseada nos limites e } \\
\text { necessidades, mas, primeiramente, vêm a } \\
\text { disponibilidade e o interesse da instituição. }\end{array}$ & $\begin{array}{l}\text { 7. Perspectiva é baseada na individualidade e } \\
\text { as necessidades do indivíduo são priorizadas } \\
\text { e não os da instituição. Se necessário, são } \\
\text { criados ou modificados serviços e suportes. }\end{array}$ \\
\hline $\begin{array}{l}\text { 8. Profissionais são pagos, especificamente, } \\
\text { para reunir informações para desenvolver } \\
\text { os objetivos do planejamento. }\end{array}$ & $\begin{array}{l}\text { 8. Membros do círculo pessoal e de parte } \\
\text { do apoio escolar também são envolvidos no } \\
\text { desenvolvimento dos objetivos do PEI. }\end{array}$ \\
\hline $\begin{array}{l}\text { 9. Planejamento é tratado como } \\
\text { um "mal necessário". }\end{array}$ & 9. Planejamento é tratado como algo promissor. \\
\hline $\begin{array}{l}\text { 10. Não tem foco na aprendizagem } \\
\text { da autodefensoria ou no exercício da } \\
\text { advocacia por familiares/pares. }\end{array}$ & $\begin{array}{l}\text { 10. Destaque no indivíduo, na família e nos amigos, } \\
\text { visando ao empoderamento para participar nos encontros } \\
\text { de planejamento. Profissionais e paraprofissionais podem } \\
\text { ser alterados durante o processo de ensino-aprendizagem } \\
\text { do estudante, mas sua família, principalmente, } \\
\text { pais e/ou responsáveis legais, permanecem. }\end{array}$ \\
\hline
\end{tabular}

Fonte: Keyes e Owens-Johnson (2003).

PEI: plano educacional individualizado. 
A partir da base do que está especificado ou previsto no planejamento educacional, os estudantes PAEE podem se beneficiar das diferenciações curriculares individualizadas, cujo objetivo é otimizar e aperfeiçoar o processo de ensinoaprendizagem e as avaliações desses estudantes (Giné e Ruiz, 1995).

Segundo os mesmos autores, o PEI deve cumprir as seguintes funções:

- estabelecer uma conexão lógica entre a avaliação psicopedagógica e a programação individual;

- preparar e coordenar as atuações educacionais regulares e especiais direcionadas ao estudante;

- proporcionar ao estudante, o máximo possível e quando convier, ambientes menos restritivos;

- eliminar, na medida do admissível e quando convier, os recursos educacionais especiais e devolver ao estudante circuitos, serviços e situações escolares os mais normais;

- descrever, especificar e justificar a resposta educacional dirigida ao estudante, de forma clara e compreensível, a fim de que todas as pessoas envolvidas no crescimento pessoal desse estudante - e o próprio estudante, sempre que possível - possam participar, efetivamente, na tomada de decisões educacionais relacionadas à elaboração, desenvolvimento e avaliação do programa individualizado (Giné e Ruiz, 1995).

Para perceber a importância do PEI, é necessário compreender que o termo educação não significa somente a escolarização promovida pela escola, mas todas as influências ocorridas na formação do estudante. Para Plaisance (2004), as principais influências na formação do estudante são:

- a frequência, que representa o tempo, de forma qualitativa e quantitativa, em que há exposição de ideias e práticas com o estudante;

- o currículo, que é dividido em três análises: o conteúdo programático da escola, denominado de padrão; o oculto, que é, sem dúvida, o mais difícil de ser mensurável, pois sua análise é subjetiva; e o real, que registra o que realmente foi transmitido e absorvido pelo estudante; $\mathrm{e}$

- a cultura na qual está inserido o estudante, em que ele será analisado em virtude de sua classe social, região, tipo de comportamento, dentre outros aspectos ligados à cultura da qual ele sofre influências.

Dentro desse pensamento, compreende-se a relevância do PEI na escolarização de qualquer estudante PAEE que não esteja, ainda, totalmente apto a ter as mesmas aprendizagens esperadas dentro do currículo padrão do ano/série que ele/ela frequenta. Por esse fator, o mesmo deve ser elaborado com a finalidade de atender às características de cada aluno (Giné e Ruiz, 1995; Castanedo, 1997; Stainback e Stainback, 1999; Fennick, 2001; Gonzalez, 2002).

Assim, em decorrência da política de inclusão escolar, os educadores do ensino regular estão recebendo um contingente crescente de estudantes PAEE cujas necessidades educacionais especiais são desconhecidas para eles que, muitas vezes, não sabem por onde começar o processo de ensino, estabelecer as diferen- 
ciações necessárias e não compreendem quais as possibilidades desses estudantes (Stainback e Stainback, 1999). Nessa direção, o PEI tem servido para diminuir a sensação de despreparo dos professores no processo de inserção desses alunos no ensino regular (Giné e Ruiz, 1995; Castanedo, 1997; Manzano, 2001; Fennick, 2001; Gonzalez, 2002).

A educação eficaz tem por base a supervisão, a concepção, a avaliação e expectativas elevadas. Importa utilizar um enquadramento curricular comum a todos os alunos. Contudo, em muitos casos, é necessária a adaptação do currículo, não apenas para os alunos que apresentem necessidades educacionais especiais (NEE) complexas, mas, também, para todos os outros alunos. Quanto aos alunos com NEE, esta abordagem é definida e implementada no âmbito do Plano de Educação Individual (PEI). (European Agency, 2006, p. 23)

Nos Estados Unidos, na Itália e na França, o processo de escolarização de pessoas PAEE prevê o planejamento cuidadoso particularizado, caso a caso, que define como serão organizados o processo e o percurso educacional do indivíduo, haja vista que, nesses países, requisitos legais e regulamentos oficiais garantem esse tipo de procedimento (Tannús-Valadão, 2010).

Nos Estados Unidos e na Itália, foram criadas leis específicas sobre o PEI centrado no indivíduo, tais como: o PL n. 101.476 Ato Educacional, para indivíduos com deficiência (IDEA, 1990); e a lei n. 104 (Itália, 1992). A França promulgou, por meio da lei n. 102 de 2005, a garantia de PEI para todo alunado PAEE do país (França, 2005).

Nos Estados Unidos, o PEI se refere aos aspectos adaptados ou modificados do programa educacional e se centra na prioridade sobre as necessidades, apesar de os estudantes também poderem demandar outras necessidades educacionais que não exigem o mesmo grau de intensidade de planejamento e monitorização. Nem todos os aspectos da vida escolar e do currículo precisam ser modificados para os estudantes PAEE, devendo apenas as áreas de necessidade identificadas na avaliação serem cobertas. $\mathrm{O}$ montante de adequação e apoio irá variar de acordo com as necessidades individuais de aprendizagem de cada estudante, podendo os estudantes com necessidades mais complexas exigirem modificações educacionais significativas (IDEA, 2004).

Na Itália, o PEI deve estar em acordo com os objetivos educacionais orientados para atender às capacidades, às habilidades e às potencialidades dos estudantes $\mathrm{PAEE}$, incluindo objetivos didáticos, de reabilitação, além dos aspectos sociais e de bem-estar. A ideia é oferecer ao estudante uma diversidade de condições, com outras atividades extracurriculares, para favorecer a transição para o trabalho, a vida adulta e a escola técnica ou o ensino superior universitário (Itália, 1992).

$\mathrm{Na}$ França, por sua vez, o PEI define precisamente os procedimentos tanto para a conduta da escolarização e das ações pedagógicas quanto para as ações psicológicas, educativas, sociais, médicas e paramédicas, a fim de satisfazer as necessidades dos estudantes PAEE (França, 2005).

Assim, a literatura da área de Educação Especial permite identificar dois modelos de planejamento ao longo da história: o centrado nas demandas da instituição e 
o centrado no indivíduo (Keyes e Owens-Johnson, 2003). Entretanto, os novos valores morais e filosóficos e as políticas de inclusão requerem a utilização do segundo tipo de planejamento (Scotch, 2001; Mendes, 2006). Isso pode ser observado claramente nos modelos de planejamento encontrados nos três países pesquisados, ou seja, a tendência para o planejamento ser cada vez mais centrado na pessoa.

Analisando os caminhos históricos pelos quais os diferentes países europeus e os Estados Unidos trilharam para o acesso à educação das pessoas com deficiência, a European Agency (2003) identificou três modelos sobre Inclusão Escolar:

1. o modelo de via única, cujas políticas e práticas são orientadas para a escolarização de quase todos os alunos no sistema regular de ensino, que é onde eles se enquadram, como no caso da Itália;

2. o caminho de duas vias distintas com dois sistemas de educação (regular e especial) separados ou paralelos com regras próprias, sendo os alunos PAEE escolarizados em classes e escolas especiais;

3. o caminho de duas vias interligadas, no qual os serviços regulares e especiais podem ser coordenados ou complementares, como se considera que seja o caso da França e dos Estados Unidos.

Apesar dessa tendência padronizada dos modelos, ainda assim se percebe, pelo menos, uma variação entre os modelos de planejamento centrado na pessoa, que se refere à abrangência ou ao escopo do planejamento. A esse respeito, o modelo que mais se diferencia é o da França, por ser mais abrangente, envolvendo a necessidade de avaliações mais globais e abrangendo não apenas a escola, mas a vida em sociedade como um todo. Ademais, o modelo francês não é restrito à idade de escolarização, mas abrange todo o ciclo vital da pessoa. A política francesa especifica, por exemplo, o direito à compensação das consequências da deficiência. Compensar significa dar respostas às necessidades das pessoas, sejam essas necessidades, por exemplo, decorrentes, entre outras coisas: das demandas da primeira infância; da escolaridade; da educação; da inserção profissional; de arranjos domiciliares; de pessoal capacitado; do desenvolvimento e da oferta de serviços e de apoios de todos os tipos; da própria pessoa ou da instituição à qual ela está vinculada, dentre outros (Mendes, 2009).

Assim, identificadas as necessidades de compensação, um plano deve ser elaborado, considerando as necessidades e as aspirações da pessoa PAEE, tais como expressas no projeto de vida.É esse plano que define se e como a pessoa terá direito aos diferentes tipos de compensações previstos na lei, como, por exemplo, benefícios de prestação continuada na forma de auxílio financeiro para cobrir despesas com ajuda humana (de auxiliares, profissionais etc.), técnica (para compra de recursos de tecnologia assistiva, por exemplo), de animais (para aquisição de cão guia para cegos, por exemplo), para adequação de moradia ou veículos, ou ainda para outros tipos de ajuda específica ou excepcional (Mendes, 2009).

Desse modo, o modelo francês é o que tem, em teoria, maior abrangência, englobando todo o ciclo vital e não sendo apenas restrito à faixa etária da escolaridade obrigatória, além de prever suportes para fora da escola e estendidos para a 
vida na comunidade. Assim, crianças e jovens em processo de escolarização podem se beneficiar de aporte financeiro para apoiar diretamente o processo de escolarização (por exemplo, pagamento dos serviços médico-sociais, serviço de orientação escolar, manutenção em estabelecimento para a infância de jovens maiores de 20 anos de idade, auxiliar de vida escolar, auxiliar de vida universitária, material pedagógico adaptado, arranjos em provas de concursos, arranjos escolares, transporte escolar etc.), atestados de invalidez, (tais como a "carta de invalidez", a "carta prioridade para pessoa com deficiência" e a "carta estacionamento para a pessoa com deficiência" que permite gozar de benefícios fiscais, acesso e assentos nos transportes, prioridade em filas de esperas), bem como a prestação continuada na forma de benefício financeiro regular.

Embora, nos demais países, tais benefícios sociais das pessoas com deficiências estejam garantidos em leis, como, por exemplo, o benefício de prestação continuada no Brasil, a diferença, em se tratando da França, é que naquele país há uma política mais integrada, de responsabilidade de uma única instituição, que são as chamadas "maisons departamentalles du handicap", responsáveis pela avaliação e pelo planejamento de todos os suportes de que o indivíduo precisa. Nos demais países, há uma distribuição dessas responsabilidades entre setores educacionais, de saúde, da assistência social, do trabalho etc., e disso decorre uma fragmentação dos serviços que dificultam avaliar o quanto as políticas de fato caminham para garantir os direitos sociais das pessoas PAEE.

Nos demais países estudados, o modelo de PEI centrado no indivíduo é mais voltado para o planejamento exclusivo da vida escolar, embora todos enfatizem a importância de se incluir medidas de controle do processo de transição da escola para a comunidade, mesmo porque a responsabilidade do sistema educacional por essas pessoas praticamente cessa por volta dos 20 ou 21 anos de idade. Assim, ao mesmo tempo em que há o reconhecimento da necessidade de ampliar o período de escolaridade obrigatória no caso dos alunos da Educação Especial, o sistema não irá acolher esse indivíduo ad infinitum, pois, ao contrário do que acontece no Brasil, a lei define até quando esses indivíduos deverão permanecer na escola. Passado esse período de escolarização obrigatória, outros sistemas de proteção ou atenção devem assumir a responsabilidade pelo futuro da vida das pessoas com deficiências, embora o processo de transição seja garantido como sendo, ainda, assumido como responsabilidade dos sistemas educacionais.

Em relação aos dois modelos de PEI encontrados, um mais geral e abrangente (França) e outro mais específico (Estados Unidos e Itália), pode-se dizer que há uma tendência maior de se adotar modelos específicos para o processo de escolarização, uma vez que dois dos três países analisados adotam esse tipo de PEI. $\mathrm{E}$ em que consiste esse PEI?

Em linhas gerais, o PEI é, ao mesmo tempo:

- um documento redigido, uma espécie de contrato, que descreve o programa educacional em termos de serviços demandados por um estudante em particular, tomando como base avaliações aprofundadas dos pontos fortes do aluno e de suas necessidades e que afetam a habilidade ou comportamento do aluno para aprender e para demonstrar a aprendizagem; 
- um registro das diferenciações individualizadas que serão necessárias para ajudar o estudante a alcançar expectativas de aprendizagem para ele estipuladas;

- um documento norteador do trabalho educacional que identifica como as expectativas de aprendizagem podem ser alteradas, levando-se em consideração as necessidades do aluno, o currículo padrão e a identificação de metas alternativas nas áreas de programas, caso necessário;

- um registro dos conhecimentos e das habilidades específicas do aluno e que permite identificar o repertório de partida, acompanhar a evolução em direção às metas e traçar novos caminhos, se determinado programa não estiver permitindo atingir as metas estabelecidas para o estudante;

- um instrumento que permite prestar contas para o aluno, para seus pais e/ou representantes legais e para todos aqueles que têm responsabilidades para que os objetivos da educação sejam cumpridos.

No tópico a seguir, aborda-se como é concebido o planejamento educacional para alunos do PAEE no Brasil.

\section{PLANO EDUCACIONAL INDIVIDUALIZADO NO BRASIL: CENTRADO NO SERVIÇO OU NO INDIVÍDUO?}

No Brasil, constata-se a existência de dispositivos em algumas leis estaduais e municipais, particularmente do começo dos anos 2000, garantindo o plano educacional que assume nomenclaturas diversas, tais como: plano de desenvolvimento individualizado - PDI - e plano de atendimento individualizado - PAI.

Em 2009, é mencionada, na Resolução n. 4, a necessidade de os sistemas assegurarem o plano de atendimento educacional especializado - plano de atendimento educacional especializado (AEE), sendo essa responsabilidade atribuída ao professor do AEE, qual seja:

Elaborar e executar plano de Atendimento Educacional Especializado, avaliando a funcionalidade e a aplicabilidade dos recursos pedagógicos e de acessibilidade. (Brasil, 2009, p. 3)

A Resolução n. 61, de 2014, do estado de São Paulo, por exemplo, estabelece que:

Artigo $9^{\circ}$ - O professor especializado, que atue em Sala de Recursos, Itinerância ou classe regida pelo professor especializado - CRPE, responsabilizar-se-á por: V - elaborar e desenvolver o Plano de Atendimento Individualizado; (São Paulo, 2014)

Tannús-Valadão (2013) analisou 200 planos de AEE de um município do interior do estado de São Paulo, elaborados entre os anos de 2011 e 2012, com o objetivo de descrevê-los e caracterizá-los. Os achados da pesquisa evidenciaram que o preenchimento desses documentos parece ser feito por mera formalidade, pois foram encontrados: 
- repetições, independentemente da série/ano e/ou do tipo de categoria de deficiência em que esse alunado se enquadrava;

- incoerências, como, por exemplo, o profissional/paraprofissional mais utilizado era o profissional de apoio ou estagiário, mas, quanto à parte do plano de AEE que previa que o professor de AEE deveria orientá-los, não havia nenhuma informação na maioria dos planos;

- ausências no preenchimento desses documentos, pois apenas um terço dos alunos PAEE do município tinham esse documento formalizado. Além disso, os resultados indicaram que muito do que se fazia sobre esse plano, nessa esfera, se centrava no planejamento das ações do professor da sala de recurso multifuncional - SRM, ou no AEE, enquanto não era evidenciada a relação com o ensino ofertado em classe comum.

Achados semelhantes foram encontrados em outros estudos (Mendes et al., 2015) quando foram analisadas as avaliações realizadas pelos professores de Educação Especial de outra rede municipal para discriminar o repertório dos alunos PAEE e, por consequência, elaborar seus planos de AEE. Além disso, os objetivos desses planos eram subjetivos e não contemplavam, necessariamente, metas pedagógicas com base nos currículos padrões das salas, conforme exposto no trecho abaixo:

A partir da identificação das habilidades (comunicação oral, linguagem escrita, dentre outras) necessárias para a escolarização do aluno, o professor de SRM definia objetivos gerais e específicos de cada área para trabalhar dentro do $\mathrm{Pla}-$ no de AEE. (Mendes et al., 2015, p. 471)

A legislação educacional brasileira, a LDB n. 9394/96, reformulada em 2013 (Brasil, 1996,2013), traz um dispositivo que garantiria um certificado de escolaridade, denominado como "terminalidade específica", cuja finalidade seria a de comprovar grau de escolarização. Entretanto, se a educação desses alunos não for devidamente avaliada e planejada, o certificado de terminalidade específica pode, além de mascarar o fracasso escolar (Iacono e Mori, 2004), excluir da escola estudantes que não avançam para o ensino médio (Lima, 2009). Tal dispositivo, em tese, pode continuar sendo utilizado para abreviar o percurso de escolarização de alunos do PAEE, ainda que a escolarização que lhes seja oferecida apresente qualidade duvidosa.

Os dados do censo escolar referentes ao número escasso de matrículas em níveis mais avançados da educação básica, como na fase II do ensino fundamental e no ensino médio, sugerem que esses estudantes PAEE parecem não estar avançando (INEP, 2016). Alguns autores apontam a razão para isso como sendo a falta de aspectos básicos como procedimentos de avaliação e monitoramento do processo de ensino-aprendizagem para comprovar se o estudante teve acesso ou não ao currículo (Mendes, Ferreira e Nunes, 2003).

Veltrone e Mendes (2009), investigando egressos de escolas e classes especiais sendo escolarizados em classes comuns, encontraram que, apesar de os alunos demonstrarem gostar do novo tipo de escolarização, esses afirmaram vivenciar sérias dificuldades de aprender o conteúdo do currículo padrão, principalmente porque 
não eram feitas diferenciações no ensino de modo a responder às necessidades dos estudantes. Os resultados sugerem a necessidade de melhorar e personalizar o planejamento educacional para atender à diversidade dos alunos.

Enfim, pode-se perceber que, no Brasil, quando há propostas de planejamento educacional destinadas a alunos do PAEE, essas podem ser consideradas como planejamentos com foco nos serviços prestados pelo professor de Educação Especial, que não são, necessariamente, centrados nos estudantes, não havendo, ainda, referências a como o ensino na classe comum é planejado.

$\mathrm{Na}$ falta de dispositivos legais e de estudos sobre os benefícios gerados com a implementação do PEI em nosso país, o caminho a prosseguir na investigação foi o de buscar referências em países que já possuíam essa prática instalada como parte da escolarização de pessoas PAEE.

O Quadro 2 caracteriza os diferentes tipos de PEI encontrados, podendo ser desde restrito ao contexto escolar, quando as habilidades a serem desenvolvidas são específicas no âmbito da escola, ou educacional, quando a referência é o ciclo de vida da pessoa inteiramente projetado, bem como sua vida para além da escola, como acontece na França. Os estudos realizados na França, Espanha, Itália e Estados Unidos indicam que a utilização do PEI e, principalmente, dos critérios de acompanhamento, como os de avaliação e reavaliação do processo de escolarização, teve efeitos positivos na educação de pessoas PAEE (França,2009; Rodríguez,2007; Fennick, 2001; Ianes e Cramerotti,2003).

Diferentes autores têm apontado como resultado do PEI a otimização e o aperfeiçoamento do processo de ensino-aprendizagem e das avaliações dos estudantes PAEE, por meio da ação compartilhada das pessoas que são responsáveis ou que

Quadro 2-Tipos de plano educacional individualizado.

\begin{tabular}{|l|c|c|c|c|}
\hline Tipo de PEI & Itália & França & Estados Unidos & Brasil \\
\hline Escolar & $\begin{array}{c}\text { Educacional (abrange } \\
\text { todo o ciclo da vida e } \\
\text { em todos os contextos) }\end{array}$ & Escolar & $\begin{array}{c}\text { Restrito ao } \\
\text { AEE - SRM; } \\
\text { Centro de AEE }\end{array}$ \\
\hline $\begin{array}{l}\text { Profissionais } \\
\text { envolvidos }\end{array}$ & $\begin{array}{c}\text { Equipe escolar, } \\
\text { profissionais } \\
\text { da saúde e } \\
\text { representante } \\
\text { legal do estudante } \\
\text { e o estudante }\end{array}$ & $\begin{array}{c}\text { Equipe escolar, da } \\
\text { saúde, representante } \\
\text { legal do estudante e } \\
\text { a pessoa público-alvo } \\
\text { da Educação Especial }\end{array}$ & $\begin{array}{c}\text { Equipe escolar, } \\
\text { profissionais da saúde, } \\
\text { representante legal do } \\
\text { estudante e o estudante }\end{array}$ & Professores de AEE \\
\hline Objetivos \\
do PEI & $\begin{array}{c}\text { Didático e } \\
\text { formativo }\end{array}$ & $\begin{array}{c}\text { Objetivos do processo } \\
\text { de escolarização e as pedagógicas, } \\
\text { psicológicas, } \\
\text { educativas, sociais, } \\
\text { médicas e paramédicas }\end{array}$ & $\begin{array}{c}\text { Objetivos mensuráveis, } \\
\text { a curto e longo prazo, } \\
\text { no tocante a habilidades } \\
\text { acadêmicas para atender } \\
\text { às necessidades sociais ou } \\
\text { comportamentais, físicas } \\
\text { ou outras necessidades } \\
\text { educacionais especiais }\end{array}$ & $\begin{array}{c}\text { Competências a } \\
\text { serem desenvolvidas, } \\
\text { os comportamentos } \\
\text { que precisam } \\
\text { ser eliminados, } \\
\text { substituídos e }\end{array}$ \\
$\begin{array}{c}\text { formados (Exemplo: } \\
\text { Minas Gerais, 2003) }\end{array}$ \\
\hline
\end{tabular}

Fonte: dados da pesquisa.

PEI: plano educacional individualizado; SEM: sala de recurso multifuncional. 
deverão trabalhar com o estudante em ambientes menos restritos, eliminando-se, na medida do possível e quando convier, os recursos educacionais especiais (Amando e McBride, 2001; Giné e Ruiz, 1995).

Na França, houve um aumento de um terço em quatro anos, de 2002 a 2006, dos alunos que passaram para os níveis liceu geral e tecnológico ou profissional (França, 2009). As pesquisas de Rodríguez (2007), Fennick (2001) e Ianes e Cramerotti; (2003) sobre, respectivamente, Espanha, Estados Unidos e Itália, evidenciam que o PEI é utilizado como variável para melhorar a escolarização da pessoa PAEE.

Por outro lado, Scotch (2001) e Cabral (2010) apontam limites da política de inclusão nos Estados Unidos e na Itália. Nos Estados Unidos, Scotch (2001) descreve que a política ainda é interpretada como colocação dos estudantes PAEE com o objetivo de conter gastos, enquanto, na Itália, Cabral (2010) aponta a dificuldade de articulação entre os serviços educacionais e da saúde, bem como a tendência dos professores das classes comuns em delegar o aluno PAEE ao cuidado do professor especializado.

Em relação à proposta do PEI, pode-se dizer que os Estados Unidos são, sem dúvida, o país mais regulamentado em relação à prática do PEI entre os países investigados. Entretanto, isso não significa que problemas não aconteçam naquela realidade. Geltner e Leibforth (2008), revisando os estudos sobre a forma como o PEI tem sido implementado nos Estados Unidos, apontaram alguns problemas, dentre os quais, o fato de que existem poucas pesquisas a respeito da efetividade do PEI.

Como se pode perceber, mesmo em países que já instituíram a prática do PEI, a educação apropriada de pessoas PAEE ainda não está devidamente garantida, porque os planos nem sempre são bem elaborados, ou, se o são, nem sempre são seguidos conforme planejado. Entretanto, em contextos em que não há nenhuma garantia de se ter um PEI, a pessoa PAEE certamente não terá meios de assegurar seu direito à educação.

\section{CONCLUSÃO}

A política de inclusão escolar no Brasil tem ocasionado crescimento contínuo de matrículas dos alunos PAEE nas escolas públicas regulares. O Brasil não possui dispositivos na legislação federal que garantam que tais estudantes tenham um PEI baseado em suas peculiaridades e, na prática, esse tipo de planejamento tem sido centrado apenas nos serviços das salas de recursos multifuncionais e nos centros de atendimento educacional especializado, ou seja, em época de política de Inclusão Escolar, temos um plano elaborado ao PAEE que é típico da fase da segregação educacional.

A diferença entre os conceitos de PEI centrado no indivíduo e de plano de AEE indica a necessidade de se modificar a política de como é elaborado o planejamento educacional para alunos do PAEE no país. Levando-se em consideração o que acontece em outros países, sugere-se a adoção do modelo de PEI centrado no indivíduo, visto que tem maior probabilidade de otimizar o processo de escolarização do PAEE em classes comuns de escolas regulares.

Embora o país requeira ainda muitas medidas para tornar seus sistemas educacionais mais inclusivos, o que significa que a adoção do PEI não vai resolver por 
si só as mazelas da inclusão escolar, esse é, sem dúvida nenhuma, um instrumento indispensável para se estabelecer como apoio à escolarização desses alunos em classe comum. Por outro lado, se continuarmos a planejar o ensino desses alunos de modo independente, na classe comum e nos serviços especializados, vamos ainda produzir muitos estudos para constatar que há queixas recorrentes de que esses alunos não estão avançando no processo de escolarização, que a escolarização para eles tem apenas função de socialização, que os professores da classe comum não sabem como ensiná-los, que alunos adolescentes e adultos precisam tomar um rumo e sair da escola básica, enfim, reforçando a descrença de que a escola comum seja afinal o melhor lugar para escolarizá-los.

\section{REFERÊNCIAS}

Alves, L. A. M. República e educação: dos princípios da escola nova ao manifesto dos pioneiros da educação. Revista da Faculdade de Letras - História - Porto, III série, v. 11, p. 165-180, 2010.

Amando, A.; McBride, M. Increasing person-centered thinking: improving the quality of person-centered planning. A manual for person-centered planning facilitators. Minneapolis, Minnesota: University of Minnesota, Institute on Community Integration. 2001.

BRAsIL. Lei de Diretrizes e Bases da Educação Nacional -LDB. Brasília:Ministério da Educação, Secretaria de Educação Especial, 1996. Disponível em: <http://portal.mec.gov.br/seesp/index. php?option=content\&task=view\&id=159\&Itemid=311 >. Acesso em: 19 jul. 2007.

Resolução n. 4. Brasília: Ministério da Educação, Secretaria de Educação Especial, 2009. Disponível em: <http://portal.mec.gov.br/dmdocuments/rceb004_09. pdf $>$. Acesso em: 19 jul. 2017.

. Decreto n. 7.611, de 17 de novembro de 2011. Dispõe sobre o atendimento educacional especializado. Brasília: Presidência da República/Casa Civil/Subchefia para Assuntos Jurídicos, 2011.

. Lei de Diretrizes e Bases da Educação Nacional - LDB. Brasília: Ministério da Educação, Secretaria de Educação Especial, 2013. Disponível em: <http://www.planalto. gov.br/ccivil_03/_Ato2011-2014/2013/Lei/L12796.htm\#art1 >.Acesso em: 19 jul.2017. CABral, L. S. A. A legislação brasileira e italiana sobre a Educação Especial: da década de 1970 aos dias atuais. 2010. Dissertação (Mestrado) - Universidade Federal de São Carlos, São Carlos, 2010.

Castanedo, C. Bases psicopedagogicas de la educación especial: evaluación e intervención. Madrid: Editora: CCS, 1997. 384 p.

European Agency. Special Education across Europe in 2003, 2003. Disponível em: $<$ http://www.european-agency.org/publications >. Acesso em: 05 ago. 2008.

Educação Especial na Europa. Respostas educativas pós $1^{\circ}$ ciclo do ensino básico (Volume 2), 2006.Disponível em: <http://www.european-agency.org/publications/ereports/ special-needs-education-in-europe-volume-2/Thematic-PT.pdf $>$. Acesso em: 06 out. 2008. FEnnick, E. Cotheaching: an inclusive curriculum for transition. Teaching Exceptional Children, v. 33, n. 6, p. 60-66, 2001. 
França. Loi n. 2005-102 pour l'égalité des droits et des chances, la participation et la citoyenneté des personnes handicapées, 2005. Disponível em: $<$ http://www.legifrance. gouv.fr/affichTexte.do?cidTexte=JORFTEXT000000809647\&dateTexte=>. Acesso em: 02 maio 2009.

. Rapport du Gouvernement au Parlement relatif au bilan et aux orientations de la politique Du handicap, Secrétariat d'Etat chargé de la Solidarité, 2009.

Geltner, J. A.; Leibforth, T. N. Advocacy in the IEP Process: Strengths-Based School Counseling in Action. Professional School Counseling, v. 12, n. 2, p. 162-165, 2008. Giné, C.; Ruiz, R. As adequações curriculares e o projeto de educação do centro educacional. In: Palacios, J.; Marchesi, A. Desenvolvimento psicológico e educação: necessidades educativas especiais e aprendizagem escolar. Tradução de Marcos A. G. Domingues. Porto Alegre: Artes Médicas, 1995. v. 3. p. 295-321.

Gonzalez, J. A. T. El currículum como marco de referencia en procesos de atención a la diversidad perspectivas curriculares para alumnos con necesidades educativas especiales. In: Palomino, A. S.; Gonzalez,J. A. T. Educación especial: centros educativos y profesores ante la adversidad. Madrid: Piramides, 2002. p. 87-108.

IAcono, J. P.; MoRi, N. N. R. Deficiência mental e terminalidade específica: novas possibilidades de inclusão ou exclusão velada? In: Anped Sul, Seminário de Pesquisa em Educação da Regiño Sul, 5., Curitiba, 2004. Anais... Curitiba: Editora Universitária Champagnat, 2004. v.1.p.1-15.

Ianes D.; Cramerotti, S. Gli alunni con Bisogni Educativi Speciali: dal Piano educativo individualizzato al Progetto di vita. L'integrazione scolastica e sociale, n. 4, p. 395-419, 2003.

Instituto Nacional de Estudos e Pesquisa Educacionais Anísio Teixeira (INEP). Sinopse Estatística da Educação Básica de 2016. Brasília: INEP, 2017. Disponível em: <http://inep.gov.br/web/guest/sinopses-estatisticas-da-educacao-basica>. Acesso em: 20 set. 2017.

ItÁLiA. Legge 05.02.1992, n. 104, 1992. Disponível em: < http://archivio.pubblica. istruzione.it/news/2006/allegati/legge104_92.pdf>. Acesso em: 20 dez. 2008.

Keyes, M. W.; Owens-Johnson, L. Developing person-centered IEPs. Intervention in School and Clinic, v. 38, n. 3, p. 145-152, January 2003.

Lima, S. R. Escolarização da pessoa com deficiência intelectual: terminalidade específica e expectativas familiares. 2009. Tese (Doutorado em Educação Especial — Educação do Indivíduo Especial) - Universidade Federal de São Carlos, São Carlos, 2009.

Manacorda, M. A. História da Educação: da antiguidade aos nossos dias. Tradução. Gaetano Lo Monaco. São Paulo: Cortez: Autores Associados, 1989. 382 p.

Manzano, E. S. Principios de Educación Especial. Madrid: Editorial CCS, 2001.

Mendes, E. G.; Cia, F.; D’Affonseca, S. M.; Tannús-Valadão, G.; Aragon, C.A.; Ripari, R. A avaliação do público-alvo da Educação Especial no município de São Carlos. In:____ _ CIA, F.; MAzo, S. (Org.). Inclusão escolar e a avaliação do público-alvo da Educação Especial. 1. ed. São Carlos: Marquezine \& Manzini, 2015.v. 2. p. 463-482. 
. A radicalização do debate sobre inclusão escolar no Brasil. Revista Brasileira de Educação, v. 11, p. 387-405, 2006.

. Breve histórico da Educação Especial no Brasil. Revista Educación y Pedagogía, v. 22, p. 93-110, 2010.

. Política do handicap e a inclusão escolar no contexto Francês. In: BAPtista, C.R.;Jesus, D. M. (Org.) Avanços em políticas de inclusão: o contexto da educação especial no Brasil e em outros países. 1. ed. Porto Alegre: Mediação, 2009. p. 29-44.

Mendes, E. G.; Ferreira, J. R.; Nunes, L. R. O. P.Integração/inclusão: o que revelam e as teses e dissertações em educação e psicologia. In: Nunes Sobrinho, F. P. (Org.) Inclusão educacional: pesquisas e interfases. Rio de Janeiro: Livre Expressão. 2003. p. 98-149.

Minas Gerais. Resolução CEE n. 451/03, de 02 de setembro de 2003. Minas Gerais, Belo Horizonte, 2003.

Mittler, P. Educação inclusiva: contextos sociais. Tradução: Windyz Brazao Ferreira. - Porto Alegre: Artmed, 2003.

Moreira, L. C.; Baumel R. C. R. C. Currículo em Educação Especial: tendências e debates. Educar, Curitiba, n. 17, p. 125-137, 2001. Editora da UFPR. Disponível em: $<$ http://ojs.c3sl.ufpr.br/ojs2/index.php/educar/article/viewFile/2072/1724>. Acesso em: 11 set. 2008.

O'Brien, C. L.; O'Brien, J. The origins of person-centered planning. A community of practice perspective. Responsive systems associates from the center on human policy, Syracuse University for the Research and Training Center on Community Living. 2000. Disponível em: <https://files.eric.ed.gov/fulltext/ED456599.pdb>. Acesso em: 10 ago. 2018.

Plaisance, E. Para uma sociologia da pequena infância. Educação e Sociologia, Campinas, v. 25, n. 86, p. 221-241, abr. 2004.

Rodríguez, E. R. Discapacidad cognitiva y Educación: Una Mirada Inclusiva. "Adaptaciones Curriculares". Apresentado em congresso de Inclusivo Escolar Bogotá. Colombia 23-24 de octubre de 2007. Disponível em: < http://www.pasoapaso.com.ve/ images/stories/variospdfs/adaptacionesruiz.pdf >. Acesso em: 10 ago. 2018.

São Paulo. Resolução SE n. 61, de 11 de novembro de 2014. Disponível em: < http:// siau.edunet.sp.gov.br/ItemLise/arquivos/61_14.HTM?Time=09/07/2015\%2013>. Acesso em: 19 jul. 2017.

Schmidt, M. A. M. S.; Garcia, T. M. F. B. Professores e produção do currículo: uma experiência na disciplina de História. Currículo sem Fronteiras, v. 7, n. 1, p. 160-170, jan.-jun. 2007.

Scotch, R. K. American Disability Policy in the Twentieth Century. In: Longmere, P. K.; Umanski, L. The neww disabilities histories: American perspectives. New York: New York University Press, 2001. p. 375-392.

Stainback, S.; Stainback, W. Inclusão: um guia para educadores. Tradução de M. F. Lopes. Porto Alegre: Artmed, 1999. 456 p. 
- Considerações contextuais e sistêmicas para a Educação Inclusiva. Inclusão Revista da Educação Especial, Ministério da Educação, Secretaria de Educação Especial, Brasília, v. 2, n. 03, p. 8-14, dez. 2006.

TAnnús-VAladẽo, G. Planejamento educacional individualizado: propostas oficiais dos Estados Unidos, França, Itália e Espanha. (Dissertação) - Universidade Federal de São Carlos, São Carlos, 2010.

. Inclusão escolar e planejamento educacional individualizado: avaliação de um programa de formação continuada para educadores. 2013. (Tese) - Universidade Federal de São Carlos, São Carlos, 2013.

U.S. Department of Education's Individuals with Disabilities Education Aст (IDEA). Education for persons with special educational needs act, 2004. Disponível em: <http://idea.ed.gov/explore/view/p/,root,dynamic,TopicalArea,1,>. Acesso em: 20 out. 2008.

Pub.L. 101-476, 1990. Disponível em: <https://www.gpo.gov/fdsys/pkg/ STATUTE-104/pdf/STATUTE-104-Pg1103.pdf>. Acesso em: 10 ago. 2018.

Veltrone, A. A.; Mendes, E. G. Inclusão e fracasso escolar: o que pensam os alunos com deficiência mental? Educação Especial, Santa Maria, v. 22, n. 33, p. 59-72, jan./ abr. 2009. Disponível em: <https://periodicos.ufsm.br/educacaoespecial/article/ viewFile/169/99>. Acesso: 10 ago. 2018.

\section{SOBRE AS AUTORAS}

Gabriela Tannús-Valadẽo é doutora em educação especial pela Universidade Federal de São Carlos (UFSCar).

E-mail: gabytannus@gmail.com

Enicéia Gonçalves Mendes é doutora em Psicologia pela Universidade de São Paulo (USP). Professora da Universidade Federal de São Carlos (UFSCar). E-mail: eniceia.mendes@gmail.com

Recebido em 30 de outubro de 2017

Aprovado em 06 de março de 2018 